\title{
Chronische myeloproliferative Erkrankungen
}

Autoren: M. Griesshammer, H. Gisslinger, H. Heimpel (Kor A. Reiter

Expertengruppe: U. Berger, H. Cario, H. Gisslinger, M. Griesshe HH. Kreipe, HM Kvasnicka, E. Lengfelder, H.L. Pahl, A. A.J. Wehmeier, R. Zankovich

\section{Definition und Basisinformation}

Als chronische myeloproliferative Erkrankungen (CMPE) werden Störungen der Blutzellbildung zusammengefasst, die durch eine neoplastische Entartung der myeloischen Zellelemente, d.h. der Stammzellen für die Granulo-, Mono-, Erythround Megakaryopoese und durch einen chronischen, aber immer irreversiblen Verlauf gekennzeichnet sind. Charakteristisch für die cMPE ist eine autonome Proliferation meist mehrerer Zellreihen des Knochenmarks mit zeitlich wechselnder Leuko-, Erythro- und/oder Thrombozytose im peripheren Blut. Die Zellen im peripheren Blut sind morphologisch und häufig auch funktionell normal. Deshalb findet man bei der mikroskopischen Betrachtung des Blutbildes zwar unreife Vorstufen, im Gegensatz zu den akuten myeloischen Leukämien aber keine morphologisch abnorme Blastenpopulation.

Während bis vor einigen Jahren auch die chronische myeloische Leukämie (CML) den cMPE zugeordnet wurde, wird diese heute als eigene Entität gesehen. Diese Trennung ist sowohl aufgrund der zugrundeliegenden genetischen Veränderungen der CML als auch der in einer eigenen Leitlinie dargestellten praktischen Handlungskonsequenzen sinnvoll. Die vorliegende Leitlinie behandelt ausschließlich die sogenannten Philadelphia-Chromosom-negativen cMPE, schließt also alle Formen aus, bei denen zytogenetisch das durch die reziproke Translokation $t(9 ; 22)$ gebildete Philadelphia-Chromosom und loder molekulargenetisch ein BCR-ABLFusionsgen nachweisbar ist.

Die so definierten cMPE umfassen unterschiedliche Geno- und Phänotypen. Die drei klassischen Formen gehören teilweise demselben Genotyp an, der durch folgende Aberrationen gekennzeichnet ist:

1) die Mutation V617F der intrazytoplasmatisch lokalisierten Rezeptor-assoziierten Januskinase 2 (JAK2-Mutation) in den klonalen Zellen der Hämatopoese $(9 ; 17 ; 29 ; 31)$,

2) die Bildung erythropoetischer Kolonien im Erythropoetin (EPO)-freien Milieu und

3) die Expression des Polycythaemia vera rubra Gens (PRV1) in reifen Neutrophilen $(32 ; 45)$.

Diese Marker werden bei über $90 \%$ der Patienten mit Polycythaemia vera und etwa $50 \%$ der Patienten mit essentieller Thrombozythämie und idiopathischer Myelofibrose konkordant gefunden. Ihr Nachweis hat in Verbindung mit anderen Risikofaktoren Bedeutung für den Zeitpunkt des Therapiebeginns und die Auswahl verschiedener Therapieoptionen. Folgende Phänotypen, deren Unterscheidung und Definition international vereinbart wurden(25) werden im Folgenden getrennt behandelt:

- Polycythaemia vera (PV) 
- essentielle Thrombozythämie (ET)

- chronische idiopathische Myelofibrose/Osteomyelofibrose (cIMF)

- nicht eindeutig klassifizierbare CMPE und durch spezielle genomische Aberrationen gekennzeichnete Sonderformen

Die einzelnen Krankheitsbilder zeigen eine charakteristische Konstellation hämatologischer und klinischer Befunde und werden nach ihren Hauptmerkmalen unterschieden. Bei einigen Patienten sind zum Zeitpunkt der Diagnose diese nicht in charakteristischer Weise ausgeprägt. Man bezeichnet die Erkrankung in diesem Stadium als "(noch) nicht klassifizierbare cMPE". In der Regel führt der weitere Verlauf zur Ausprägung der unterschiedlichen Merkmale und lässt dann die Zuordnung zu einer der genannten Formen zu. Bei identischem Genotyp kommen Übergänge vom Phänotyp der ET zur PV und der cIMF vor. Die Unterscheidung, welcher klinische Phänotyp primär vorlag ist dann nur aus den anamnestischen Daten möglich.

CMPE sind Krankheiten des höheren Lebensalters. Der Zeitpunkt der Diagnose liegt bei den meisten Patienten im 5. und 6. Lebensjahrzehnt. Die Inzidenz liegt bei etwa 1:100 000/Jahr (Tab. 1), die daraus geschätzte Prävalenz bei etwa $10^{-4}$. Wenn die Krankheit im jüngeren und mittleren Lebensalter beginnt, ist die Überlebenszeit wegen geringerer Komorbidität länger als bei älteren Menschen, die relative krankheitsbezogene Mortalität aber höher. CMPE kommen nur selten bei Kindern und Jugendlichen vor. Sie erfordern hier eine besonders sorgfältige Diagnosesicherung mit Abgrenzung hereditärer, phänotypisch ähnlicher Formen, und in jedem Einzelfall die Prüfung, ob eine allogene Stammzelltransplantation (SZT) als einzige Behandlung mit kurativem Therapieziel durchgeführt werden sollte.

Tabelle 1 Epidemiologie der cMPE. Inzidenz Neudiagnosen /100 000 Einwohner und Jahr. Die Inzidenzzahlen der ET sind möglicherweise etwas zu hoch, die der cIMF zu niedrig, da präfibrotische Stadien der cIMF mit Thrombozytose als ET klassifiziert wurden. S. auch (30)

\begin{tabular}{|l|l|l|l|l|}
\hline & Inzidenz & $18-30$ Jahre & 30 - 50Jahre & $>50$ Jahre \\
\hline PV & 0,7 & $2 \%$ & $11 \%$ & $87 \%$ \\
\hline ET & 0,9 & $3 \%$ & $22 \%$ & $75 \%$ \\
\hline CIMF/IMF 0,3 & $<1 \%$ & $5 \%$ & $94 \%$ \\
\hline
\end{tabular}

\section{Polycythaemia vera}

\subsection{Definition und Basisinformation}

Die Polycythaemia vera (PV) ist eine Erkrankung der hämatopoetischen Stammzelle, die zu einer von EPO unabhängigen, irreversiblen und progredienten Erhöhung der Erythrozytenproduktion führt. Zusätzlich findet sich, meist bereits im Anfangsstadium und immer im Verlauf, eine gesteigerte Proliferation auch der Granulopoese und Megakaryopoese. Die Proliferation der Erythropoese steht jedoch im Vordergrund 
und bestimmt das klinische Bild. Folge der erhöhten Blutviskosität durch die Zunahme des Hämatokrits sind symptomatische Mikrozirkulationsstörungen und ein erhöhtes Risiko für thromboembolische Komplikationen. Das Risiko wird durch eine erhöhte Thrombozytenzahl und den zumeist gleichzeitig vorhandenen Funktionsdefekt der Thrombozyten zusätzlich erhöht. Die Rate thromboembolischer Komplikationen mit 3 bis $5 \%$ pro Jahr nach Diagnose und 20 bis $40 \%$ im Gesamtverlauf liegt eindeutig über dem Risiko der vergleichbaren Bevölkerung. Bei bereits abgelaufenen thromboembolischen Ereignissen und in höherem Lebensalter nimmt das Thromboembolierisiko zu (24). Die Rate an Blutungen, deren Auftreten besonders durch eine hohe Thrombozytenzahl begünstigt wird, liegt unter $5 \%(33)$. Das mediane Alter bei Diagnosestellung liegt zwischen 60 und 65 Jahren. Die Lebenserwartung der älteren Patienten ist bei guter Einstellung der Blutwerte gegenüber der Normalbevölkerung nur wenig eingeschränkt (38).

Selten sind jüngere Erwachsene, Jugendliche oder Kinder betroffen (s. Tabelle 1), einige von diesen Fällen sind mit dem familiären Auftreten myeloproliferativer Erkrankungen vergesellschaftet (11). Der genetische Hintergrund der familiären wie der kindlichen PV ist ungeklärt. Auch sehr junge Patienten können an lebensbedrohlichen thromboembolischen Komplikationen der PV erkranken (12).

Ebenso wie bei den anderen Formen der cMPE sind zwei klinische Stadien zu unterscheiden:

Eine chronische Phase mit erhöhter Erythrozytenproduktion und Erythrozytose, die bis zu 20 Jahren bestehen kann und

eine progrediente Spätphase (früher im angloamerikanischen Sprachgebrauch als ,spent phase' bezeichnet), die durch eine periphere Zytopenie, extramedulläre Hämatopoese mit rasch zunehmender Splenomegalie und sekundärer Markfibrose gekennzeichnet ist. Probleme der fortgeschrittenen Erkrankung sind die Entwicklung des Vollbildes der Myelofibrose mit teilweise exzessiver Splenomegalie bei bis zu $25 \%$ der Patienten, gehäuften bakteriellen Infekten und Bildung von Autoantikörpern gegen Erythrozyten und/oder Thrombozyten. Bei etwa 10\% der Patienten beobachtet man einen Übergang in eine Myelodysplasie oder akute myeloische Leukämie $(14 ; 24)$.

\subsection{Leitbefund Erythrozytose als diagnostisches Problem}

Die PV ist in erster Linie gegenüber sekundären (reaktiven) Erythrozytosen (früher auch als Polyglobulie bezeichnet) und den sehr seltenen nicht den cMPE zugehörigen Formen der angeborenen primären Erythrozytosen abzugrenzen. Dabei sind folgende Formen zu berücksichtigen:

1. Die Stresserythrozytose durch Verminderung des Plasmavolumens (Pseudopolyglobulie), bei starken Rauchern verstärkt durch einen erhöhten Anteil oxydierten Hämoglobins durch Kohlenmonoxidbildung. Sie betrifft vor allem Männer im jüngeren und mittleren Lebensalter mit isolierter grenzwertiger oder mäßiger Erhöhung der Erythrozytenzahl, der Hämoglobinkonzentration und des Hämatokrits. Die Abgrenzung von Frühformen der PV ist bei Fehlen der positiven Kriterien der PV gelegentlich nur durch Verlaufsbeobachtung möglich. Die O2-Sättingung und die EPOKonzentration sind normal. 
2. Passagere Erythrozytose mit gleichzeitiger Erhöhung von Hämatokrit und Hämoglobinkonzentration aufgrund einer Reduktion des Plasmavolumens bei schwerer Exsiccose. Die Abgrenzung ergibt sich aus dem klinischen Bild.

3. Die erworbene sekundäre Erythrozytose infolge arterieller Hypoxie bei chronischen Herz- und Lungenerkrankungen. Die O2-Sättigung ist vermindert, die EPO-Konzentration liegt im oberen Normbereich oder ist erhöht. Bei Jugendlichen und Erwachsenen des mittleren Lebensalters ist die häufigste Ursache ein Herzfehler mit venös-arteriellem Shunt, im mittleren und höheren Lebensalter eine chronische Lungenerkrankung, vor allem die COPD. Bei zusätzlicher neutrophiler Leukozytose oder einer Splenomegalie ist das gleichzeitige Bestehen einer PV auszuschließen.

4. Andere erworbene sekundäre Erythrozytosen z.B. infolge renaler Veränderungen (Zystenniere, Nierenarterienstenose) oder infolge einer autonomen EPO-Produktion in Tumoren (Nierenzellkarzinom, Leberzellkarzinom, Hepatom, Phäochromozytom, Hämangioblastom). Die O2-Sättigung ist normal, die EPO-Konzentration in unterschiedlichem Ausmaß erhöht.

5. Angeborene Erythrozytosen: Sporadisch oder familiäre primäre angeborene Erythrozytose infolge Erythropoietinrezeptor-Mutationen, die zur erhöhten EPO-Sensitivität erythroider Vorläufer führen. EPO erniedrigt oder im untersten Normbereich (stets < 10U/ml, meist $<5 \mathrm{mU} / \mathrm{ml}$ ). Sekundäre Erythrozytosen: Hämoglobinopathie mit erhöhter Sauerstoffaffinität oder 2,3-DPG-Mangel (z.B. 2,3-DPG-Mutase-Defizienz). EPO vor Aderlass hochnormal oder erhöht. Erythrozytosen aufgrund eines angeborenen Defekt der EPO-Genregulation bei Mutationen im von-Hippel-Lindau-Gen (z.B. Chuvash-Polyzythaemie). EPO vor Aderlass selten noch im oberen Normbereich, meist erhöht, Erhöhung unterschiedlich ausgeprägt.

6. Erythrozytosen bei Störungen der Hämoglobinbildung bei normaler O2Affinität des Hämoglobins. Dies betrifft vor allem die heterozygote betaThalassämie, aber auch die alpha-Thalassämia minor und leichte Eisenmangelanämien. Hämoglobinkonzentration, Hämatokrit und mittleres Erythrozytenvolumen sind vermindert. Die O2-Sättigung ist normal, die EPOKonzentration ist erhöht.

Bei Erythrozytose und gleichzeitiger Leukozytose und/oder Thrombozytose und/oder Splenomegalie ist eine cMPE sehr wahrscheinlich. Sogenannte Übergangsfälle zwischen ET und PV, die sich erst im späteren Verlauf bei Fehlen einer initial durchgeführten Knochenmarksuntersuchung (47) zu einer der beiden Entitäten eindeutig zuordnen lassen ((1), sind JAK2 und PRV1 positiv (18;22).

Schwierig kann die Abgrenzung von PV-Fällen mit reiner Erythrozytose von sekundären Erythrozytosen sein, wobei der Hkt unter der von der WHO geforderten Grenze liegen kann. Hierbei ist an Frühfälle von PV oder Fälle mit nur langsamem Krankheitsprogress zu denken. Im Einzelfall ist auch bei sekundärer Erythrozytose eine begleitende reaktive Erhöhung von Leukozyten und Thrombozyten möglich, deren Zuordnung in der Regel im Rahmen einer internistischen Gesamtbeurteilung des Patienten möglich ist. Der Nachweis einer JAK2-Mutation oder einer erhöhten PRV1-Expression schließt eine andere primäre oder sekundäre Erythrozytose aus. 


\subsection{Diagnostisches Vorgehen bei Erstfeststellung einer Erythrozytose}

Zunächst ist aufgrund der klinischen Daten und der Laborbefunde abzuschätzen, ob eher eine sekundäre Erythrozytose oder eine PV vorliegt. Hierbei sind besonders die Anamnese und Voruntersuchungen, insbesondere Verlaufswerte des Blutbildes über die letzten Monate und Jahre wichtig. Sinnvolle diagnostische Maßnahmen sind:

- Anamnese: Symptome aquagener Juckzreiz, Kopfdruck, Schwindel), arterielle oder venöse thromboembolische Ereignisse, Mikrozirkulationsstörungen, Blutungen, Nikotinkonsum, bekannte Hypertonie, Hinweise auf Herz- oder Lungenkrankheiten oder maligne Tumoren

- Körperliche Untersuchung: kardiopulmonaler Auskultationsbefund, Milz- und Lebergröße, Mikrozirkulationsstörungen

- Labor: Blutbild einschließlich Differentialblutbild, BSG oder CRP, LDH, Ferritin, Quick, PTT, AST, ALT, yGT, alkalische Phosphatase, Bilirubin, Harnsäure

- Bestimmung der EPO Konzentration im Serum

- arterielle Blutgasanalyse

- Sonographie des Abdomens

- Röntgenuntersuchung des Thorax

- EKG, Echokardiogramm, Lungenfunktion

Folgende Symptome und Befunde sprechen für das Vorliegen einer PV

- Arterielle oder venöse thromboembolische Ereignisse in den Vorjahren

- Mikrozirkulationsstörungen wie Akrozyanose, Raynaud-Syndrom, Erythromelalgie, Augenflimmern, Amaurosis fugax, Schwindel

- Juckreiz insbesondere nach warmem Baden oder Duschen

- Zusätzliche Leuko- und Thrombozytose

- Linksverschiebung und/oder einzelne Erythroblasten im Blutausstrich

- Splenomegalie

\subsection{Diagnosesicherung}

Weisen die klinischen und laborchemischen Befunde eindeutig in die Richtung einer sekundären (reaktiven) Erythrozytose, so wird die entsprechende Grunderkrankung internistisch abgeklärt und behandelt. Anderenfalls sind zum Ausschluss oder Beweis einer PV oder einer hereditären Erythrozytose folgende Untersuchungen durchzuführen:

- Kontrolle der Epo-Konzentration im Serum 
- Molekulargenetische Untersuchungen: JAK2-Mutation. BCR-ABL-Fusionsgen nur wenn JAK2 negativ

- Hämoglobinanalyse, ggf. O2- Bindungskurve

- Knochenmark: Aspirationszytologie und Histologie mit Eisen- und Faserfärbung. Mitbeurteilung in einem Referenzzentrum.

- Bei Verdacht auf hereditäre Erythrozytose: Molekulargenetische Untersuchungen des EPO-Rezeptor-Gens (Exon 7 u. 8) bei niedrigem EPO, des von Hippel-Lindau - Gens bei normalem oder erhöhtem EPO

Die Bestimmung der Erythrozytenmasse mit ${ }^{51} \mathrm{Cr}$-markierten Erythrozyten wird in Deutschland im Gegensatz zur Praxis den meisten angelsächsischen Institutionen nicht mehr empfohlen und in den WHO-Kriterien auch nicht mehr gefordert. Sie erlaubt lediglich die Abgrenzung der Stress-Erythrozytose und ist gerade in diagnostisch schwierigen Grenzfällen unzuverlässig oder irreführend (28).

Der Diagnosebeweis ergibt sich aus den modifizierten WHO Kriterien:

A1 Erythrozytenzahl über 5,5 G/l (5,0 G/l) oder Hb über 18,5 g/dl (16,5 g/d) oder Hkt über 52\% (49\%) bei Männern oder (Frauen)

A2 Ausschluss einer sekundären Erythrozytose: o. kongenitalen primären Erythrozytose

S. 0 .

A3 JAK2-Mutation in kernhaltigen Blut- oder Knochenmarkzellen, oder PRV1Expression in reifen Neutrophilen oder klonale zytogenetische Aberration in Knochenmarkzellen außer Ph-Chromosom

A4 Bildung erythropoetischer Kolonien im EPO-freien Milieu

A5 Splenomegalie

B1 Thrombozytenzahl $>450 \times \mathrm{G} / \mathrm{L}$

B2 Leukozytenzahl $>12 \times \mathrm{G} / \mathrm{L}$

B3 Vermehrung der myelopoetischen Zellen im Knochenmark mit Prominenz der Erythroblasten und Megakaryozyten

B4 Verminderte oder niedrig-normale EPO-Konzentration im Serum

Die Diagnose gilt als gesichert, wenn A1 plus A2 oder A3, und eine der anderen Kategorien von A oder zwei der Kategorien von B vorliegen. 


\subsection{Therapie}

Die Therapieziele sind im mittleren und höheren Lebensalter palliativ und umfassen

- die Beseitigung oder Linderung von Symptomen, welche die Lebensqualität einschränken,

- die Verhinderung von thromboembolischen Ereignissen

- die Verlängerung der Lebenserwartung durch Verschiebung der späten Komplikationen, Myelofibrose und Myelodysplastisches Syndrom (MDS)/akute Leukämie, für die bisher allerdings keine beweisenden Daten vorliegen.

Eine kurative Therapie der PV ist nur durch eine allogene SZT möglich (s.u.).

Allgemeine Maßnahmen zur Senkung des Tromboembolierisikos: Gewichtsnormalisierung, regelmäßige Bewegung, Vermeiden von Exsiccose und langem Sitzen, effektive Behandlung kardiovaskulärer Krankheiten, Information der Patienten über Frühsymptome einer Thrombose und der Notwendigkeit des sofortigen Arztkontaktes

\section{Aderlasstherapie}

Aderlässe sind die schnellste und einfachste Maßnahme zur Normalisierung von Erythrozyten- und Gesamtblutvolumen, zur Absenkung des Hkt und der Beseitigung der Hyperviskosität. Man beginnt mit der Abnahme von 250 bis 500 ml in zwei- bis dreitägigen Abständen, bis der Hkt unter 45\% gesenkt ist. Bei älteren Menschen oder bei Kreislaufbeschwerden nach dem ersten Aderlass wird die anschließende Gabe von $500 \mathrm{ml}$ einer isotonischen Lösungen empfohlen, obwohl eine Verminderung der sowieso niedrigen Komplikationsrate nicht bewiesen ist. Allerdings ist unter alleiniger Aderlasstherapie die Thromboserate erhöht, so dass bei Fehlen von Kontraindikationen die Gabe von ASS empfohlen wird (s.u.).

Die Aderlassfrequenz ist im Verlauf den Hkt-Werten anzupassen, deren Optimum individuell unterschiedlich zwischen 40 und 45\% liegen kann. Nach Möglichkeit sollte der Hkt möglichst gleichmäßig auf einen Wert von $\leq 45 \%$ eingestellt werden.

Der immer eintretende Eisenmangel wird nicht substituiert. Ziel ist das Erreichen einer eisendefizitären Erythropoese mit Zinkprotoporphyrinwerten (ZPP) zwischen 100 und $150 \mathrm{~mol} / \mathrm{Mol} \mathrm{Häm}$ (Normal <40) oder MCV-Werten unter 75fl. Die Aderlasstherapie senkt die Thrombozytenzahl nicht, sondern führt eher zu einem Thrombozytenanstieg. Sie wird auch unter zytoreduktiver Therapie fortgeführt, um die Hkt-Werte ohne Dosissteigerung im gewünschten Bereich zu halten.

Als Alternative zu Aderlässen kann die Erythrozytapherese an dafür ausgestatteten Einrichtungen werden.

\section{Thrombozytenaggregationshemmer}

Acetylsalizylsäure (ASS) 100 mg /Tag ist bei Patienten, die keine Kontraindikation haben (z. B. bei vorausgegangenen Blutungskomplikationen, Ulcusanamnese) zur Primärprophylaxe von arteriellen Thrombosen indiziert, auch wenn gleichzeitig eine 
zytoreduktive Therapie durchgeführt wird (33). Periphere und zerebrale Mikrozirkulationsstörungen sprechen gut auf ASS an und sind eine symptombezogene Indikation.

Vor Beginn der ASS-Therapie empfiehlt sich eine Absenkung einer erhöhten Thrombozytenzahl möglichst unter $600000 / \mu$ l. Bei einer Thrombozytenzahl $\geq 1 \mathrm{Mio} . / \mu \mathrm{l}$ sollte wegen des erhöhten Blutungsrisikos kein ASS verabreicht werden, sondern erst wenn die Thrombozyten durch zytoreduktive Behandlung abgesenkt worden sind.

\title{
Zytoreduktive Therapie
}

Es gibt keine gesicherten Daten zum optimalen Zeitpunkt für die Einleitung einer zytoreduktiven Therapie. Aufgrund nicht-randomisierter Studien $(1 ; 10 ; 24 ; 43)$ wird der Beginn empfohlen bei mindestens einem der folgenden Kriterien:

\author{
Zeichen der unkontrollierten Myeloproliferation \\ Zunahme der Milzgröße oder symptomatische Splenomegalie \\ Thrombozyten >600G/l \\ Leukozyten >25 G/L \\ Notwendige Aderlassfrequenz von über 12 pro Jahr \\ Leukoerythroblastisches Blutbild
}

\section{Gesteigertes Risiko für Thromboembolien, klinische Symptome}

Thromboembolische oder hämorrhagische Komplikationen

Mikrozirkulationsstörungen trotz ASS

Bekannte kardiovaskuläre Risikofaktoren, koronare Herzkrankheit)

Symptomatischer Eisenmangel, der eine Fortführung der Aderlässe nicht erlaubt oder eine Eisensubstitution erfordert

Primäre Standardtherapie ist im höheren Lebensalter Hydroxyurea in einer Anfangsdosis von $20 \mathrm{mg} / \mathrm{kg} \mathrm{KG/} \mathrm{Tag.} \mathrm{Die} \mathrm{Dosis} \mathrm{ist} \mathrm{in} \mathrm{Kombination} \mathrm{mit} \mathrm{der}$ Fortführung der Aderlasstherapie anzupassen, um die gewünschten Blutbildwerte zu erreichen. Eine Steigerung auf $40 \mathrm{mg} / \mathrm{kg} / \mathrm{Tag}$ ist möglich.

Über die Altersgrenze besteht ebenso wie bei anderen cMPE keine Einigkeit. Sie wird teilweise bei einem Alter von 40 Jahren (4), teilweise bei 60 Jahren angesetzt.

Bei jüngeren Patienten, oder bei Versagen oder Unverträglichkeit der Standardtherapie:

Interferon-a (IFN) 3 × 3 Mio. IE/Woche s.c., Steigerung der Dosis nach Blutbild und Verträglichkeit, alternativ pegyliertes IFN (z.B. Peglntron 50 gg/Woche s.c., individuelle Steigerung bis auf $150 \mu \mathrm{g} /$ Woche)(35) 
Anagrelide $1-2 \mathrm{mg} / \mathrm{d}$ in allen Altersgruppen bei durch andere zytoreduktive Medikamente nicht einstellbarer hoher Thrombozytenzahl ggf. in Kombination mit Hydroxyurea oder IFN. Anagrelide führt in Kombination mit ASS zu einem erhöhten Blutungsrisiko (27)

Imatinib kann die gesteigerte Myeloproliferation bei der PV bremsen(41). Ob dies zu einem therapeutischen Nutzen führt, ist unklar. Die Therapie mit Imatinib und anderen Tyrosinkinasehemmern ist nur innerhalb von Studien gerechtfertigt.

\section{Milzbestrahlung und Splenektomie}

Die Milzbestrahlung in niedrigen fraktionierten Dosen und die Splenektomie (hohes Morbiditäts- und Mortalitätsrisiko bei Splenektomie) sind Einzelfällen mit Splenomegalie-bedingten Problemen im späten Krankheitsstadium vorbehalten. Sie sind nur unter strenger Indikationsstellung und in enger Kooperation mit dem Strahlentherapeuten bzw. Chirurgen durchzuführen. Wichtig ist die Vor- und Nachbehandlung mit Hydroxyurea zur Thromboembolieprophylaxe und zur Vermeidung einer schnellen Größenzunahme der Leber.

\section{Allogene Knochenmark- bzw. periphere Blutstammzelltransplantation}

Sie ist bei Kindern und Jugendlichen und bei Erwachsenen mit einem Ersterkrankungsalter von unter 35 Jahren zu prüfen und setzt nach dem derzeitigen Stand das Vorhandensein eines HLA-kompatiblen Geschwisterspenders voraus. Eine Reduktion der Transplantations-bedingten Mortalität ist analog zu den Daten bei der clMF wahrscheinlich durch den Einsatz einer Konditionierung mit reduzierter Dosis zu erreichen.

\section{Besondere Situationen}

\section{Kinderwunsch und Schwangerschaft}

In Analogie zur ET ist mit einer erhöhten Rate an Spontanaborten zu rechnen. Das Risiko für die Mutter ist erhöht $(3 ; 37)$ und erfordert die engfristige Überwachung durch Geburtshelfer und Hämatologen. Die Indikation zur Interruptio aus medizinischen Gründen ist im Regelfall nicht gegeben.

Die optimale Therapie der PV während einer Schwangerschaft ist nicht bekannt. Sollte im Einzelfall eine Zytoreduktion während der Schwangerschaft erforderlich sein, scheint die Gabe von IFN am geeignetsten. Es gibt für diese Indikation allerdings keine Zulassung für IFN. Niedrig dosiertes ASS kann aufgrund der Datenlage bei der ET auch für die PV empfohlen werden. In den ersten 6 Wochen nach der Geburt soll niedrig dosiertes ASS fortgesetzt werden. Bei vorausgegangenen arteriellen oder venösen Thrombosen empfiehlt sich die Kombination mit niedermolekularem Heparin (26).

\section{Operative Eingriffe}

Wichtig ist die gute Einstellung der Blutwerte (Hkt und Thrombozytenzahl) vor der Operation. Bei schlecht kontrollierten Blutbildwerten besteht ein deutlich erhöhtes 
Operationsrisiko. ASS sollte eine Woche vor dem geplanten Eingriff abgesetzt werden, perioperativ wird eine Antikoagulation mit Heparin empfohlen.

\subsection{Verlaufskontrollen}

- Klinische Untersuchung, Blutbild und Thrombozytenzahl: Abstände abhängig von der Therapieform und der Therapiephase sowie dem individuellen Verlauf der Erkrankung. In der Initialphase der Therapie kurzfristig, nach Erreichen einer stabilen Phase in der Regel einmal monatlich. Gelegentlich ergeben sich lange aderlassfreie Phasen, in denen eine Verlängerung der Kontrollabstände möglich ist.

- Vierteljährliche Kontrollen des klinischen Status und der Laborbefunde unter Berücksichtigung zu erwartender Therapienebenwirkungen und Komplikationen der Erkrankung.

- Die jährliche Untersuchung sollte mit Ausnahme der molekulargenetischen Befund dem Programm der Diagnostik im Rahmen der Diagnosestellung entsprechen.

- Verlaufsuntersuchungen des Knochenmarkes zur Erfassung der seltenen Übergänge in eine akute Leukämie oder Myelofibrose richten sich nach dem individuellen Verlauf, in der Regel werden Untersuchungen alle 2-3 Jahre empfohlen

\section{Essentielle Thrombozythämie}

\subsection{Definition und Basisinformation}

Die essentielle Thrombozythämie (ET) betrifft in erster Linie die megakaryozytäre Zellreihe. Leitbefund ist die konstante und häufig langsam progrediente Erhöhung der Thrombozytenzahl. Im Knochenmark sind die Megakaryozyten stark vermehrt und oft deutlich vergrößert, hyperlobuliert und in Gruppen gelagert (49). Da spezifische und sensitive Marker fehlen, verlangt die Diagnose zunächst den Ausschluss der häufigeren reaktiven Ursachen einer sekundären Thrombozytose, in zweiter Linie den Ausschluss anderer Formen der primäre Thrombozytosen. Wegen der allgemeinen Verfügbarkeit von automatischen Plättchenzählgeräten wird sie heute häufiger und auch bei jüngeren Patienten diagnostiziert. Zur Abgrenzung des präfibrotischen Stadiums der cIMF mit initialer Thrombozytose s. unter 4.

\subsection{Symptome und Befunde}

\section{Leitbefund Thrombozytenerhöhung als diagnostisches Problem}

Der Befund einer erhöhten Thrombozytenzahl (Thrombozytose) stellt in der Routinediagnostik eine wichtige diagnostische Herausforderung dar. Die ET ist zunächst gegenüber den häufigerer sekundären (reaktiven) Thrombozytosen $(20 ; 40)$ und den nicht den cMPE zugehörigen Formen der primären Thrombozytosen abzugrenzen. Dabei sind folgende Formen zu berücksichtigen: 
1. Akute kurzfristige Thrombozytose bei akuter Blutung, nach Trauma, großen operativen Eingriffen, akuten bakteriellen Infekten und akuter schwerer körperlicher Anstrengung. Die Diagnose ergibt sich aus der Anamnese und Verlaufskontrollen

2. Länger bestehende Thrombozytosen bei chronischen infektiösen und nichtinfektiösen entzündlichen Krankheiten. Die Diagnose ergibt sich aus dem klinischen Befund und Entzündungsreaktionen wie CRP oder BSG.

3. Thrombozytose bei Eisenmangel. Die Diagnose ergibt sich aus dem klinischen Befund, der Mikrozytose und der verminderten Ferritinkonzentration im Serum.

4. Thrombozytose bei Milzverlust oder funktioneller Asplenie bei der Sichelzellerkrankung. Die Diagnose ergibt sich aus der Grundkrankheit.

Sekundäre Thrombozytosen zeigen nur selten Plättchenzahlen von über 1000G/I und sind nicht mit einem erhöhten Thromboembolie- und Blutungsrisiko verbunden. Ausnahmen sind langzeitig persistierende Thrombozytosen bei Fortbestand einer schweren Hämolyse oder ineffektiven Erythropoese.

\subsection{Diagnostisches Vorgehen bei erhöhter Thrombozytenzahl}

Zunächst ist aufgrund der klinischen Daten und der Laboratoriumsbefunde abzuschätzen, ob eher eine sekundäre oder eine primäre Thrombozytose bei CML, PV, cIMF oder eines MDS vorliegt. Hierbei sind besonders Voruntersuchungen und falls verfügbar, Verlaufswerte des Blutbildes über die letzten Monate und Jahre wichtig. Sinnvolle diagnostische Maßnahmen sind:

- Anamnese: insbesondere Symptome und Befunde von Mikrozirkulationsstörungen, arterielle oder venöse thromboembolische Komplikationen oder Blutungen

- Körperliche Untersuchung: insbesondere Leber- und Milzgröße

- Labor: Blutbild einschließlich Differentialblutbild, BSG oder CRP, LDH, Ferritin, Quick, PTT, AST, ALT, g-GT, alkalische Phosphatase, Bilirubin, Kreatinin, Harnsäure

\section{- Sonographie des Abdomens}

- Röntgenuntersuchung des Thorax (nur wenn V.a. sekundäre Thrombozytose)

Folgende Befunde sprechen für das Vorliegen einer ET oder einer anderen Form der cMPE:

1. Langjährig erhöhte Thrombozytenzahlen

2. Thrombozytenzahlen von über $1000 \mathrm{G} / \mathrm{l}$

3. Vorliegen von Mikrozirkulationsstörungen, arteriellen oder venösen thromboembolischen Komplikationen, oder Blutungen

4. Splenomegalie 
5. Neutrophile Leukozytose ohne Erhöhung der Entzündungsparameter, leukoerythroblastisches Differentialblutbild oder Erhöhung des Hkt

6. JAK2-Mutation und/oder erhöhte PRV1-Expression

Findet sich eine eindeutige oder sehr wahrscheinliche Grunderkrankung zur Erklärung der Thrombozytose so ist zunächst die Verlaufsbeobachtung, wenn möglich nach Elimination der angenommenen Ursache vertretbar. Sollte die Thrombozytose ohne eindeutige Ursache persistieren, die Thrombozytenzahl weiter ansteigen oder sich nach den oben genannten Untersuchungen die Hinweise auf das Vorliegen einer primären Thrombozytenerhöhung verdichten, sind zusätzlich folgende Untersuchungen durchzuführen:

- Knochenmark: Zytologie und Histologie mit Eisen- und Faserfärbung. Mitbeurteilung in einem Referenzzentrum.

- Molekulargenetische Untersuchungen: JAK2-Mutation, BCR-ABL-Fusionsgen

Findet sich ein Philadelphia Chromosom und loder ein BCR-ABL-Fusionsgen, so ist auch bei zunächst selektiver Thrombozytose die Diagnose einer CML gesichert. Findet sich eine JAK2-Mutation, so ist die Diagnose einer primären Thrombozytose im Rahmen einer cMPE gesichert. Die weitere Diagnostik reduziert sich dann auf die Frage, ob eine ET oder Thrombozytose bei einer anderen Form der cMPE vorliegt. Ein negatives Ergebnis schliesst eine ET nicht aus, da nur bei etwa 50\% der Fälle die genannten molekularen Marker zu finden sind.

Die Diagnosesicherung der ET erfolgt nach den modifizierten WHO-Kriterien (51):

Positive Kriterien

A1 Plättchenzahl anhaltend $>600 \times 10^{9} /$;

A2. ET-typische Knochenmarkhistologie mit vergrößerten, reifen Megakaryozyten

A3. Nachweis der JAK2-Mutation oder der Überexpression von PRV1

und

Ausschlußkriterien

B1 Ausschluß einer PV, CML, cIMF, MDS, reaktiven Thrombozytose

Die Knochenmarkdiagnostik (Zytologie und Histologie) spielt eine zentrale Rolle (Kriterium A2!). Sie erlaubt beispielsweise die Abgrenzung einer präfibrotischen cIMF (s.4) gegenüber einer klassischen $\mathrm{ET}$.

Die Diagnose ET ist gesichert, wenn A1 plus $A 2$ und B1 oder A2 plus A3 und B1 erfüllt sind. Allerdings gibt es Übergangsfälle zwischen ET und PV, welche sich erst im späteren Verlauf zu einer der beiden Entitäten eindeutig zuordnen lassen. Neuere Daten zeigen, dass diese meist JAK2 und PRV1 positiv sind (18;23). Selbstverständlich gibt es Frühfälle mit nur mäßig erhöhten Thrombozytenzahlen (36), bei denen die Diagnose einer ET oder des präfibrotischen Stadiums einer cIMF durch Nachweis der Jak2-Mutation gestellt werden kann. 


\subsection{Therapie}

Eine kurative Therapie ist nicht bekannt. Die Wahl der Behandlung ist immer ein Kompromiss zwischen der Behandlung ET-bedingter Beschwerden und Risiken einerseits und dem Auftreten medikamentös bedingter Nebenwirkungen andererseits $(5 ; 23)$. Aufgrund des variablen klinischen Verlaufs richtet sich die therapeutische Strategie an einer individuellen Risikostratifizierung aus. Risikofaktoren für das Auftreten ET-bedingter thromboembolischer Komplikationen sind (19):

1. Anamnestisch bekannte thromboembolische Komplikationen oder schwere Blutungen.

2. Alter über 60 Jahre.

3. Thrombozytenzahlen über $1.500 \times 10^{9} / \mathrm{l}$ (nur für Blutungskomplikationen bewiesen).

4. ET unabhängige kardiovaskuläre Risikofaktoren (arterielle Hypertonie, Diabetes mellitus, Hypercholesterinämie oder Nikotinabusus)

5. Vorliegen von thrombophilen Markern (z.B. Homozygotie bei Faktor $V$ Leiden oder der Prothrombinmutation, Kombinationsdefekte wie z.B. heterozygote Faktor $\mathrm{V}$ Leidenmutation und Prothrombinmutation oder Vorliegen von Lupusinhibitoren)

6. Vorliegen einer JAK2-Mutation oder einer PRV-1- Überexpression

\subsection{Risikostratifikation}

Um für den individuellen Patienten eine optimale Behandlungsstrategie zu finden, wird zunächst eine Risikostratifikation vorgenommen. Diese unterteilt Hoch-, Intermediär- und Niedrig-Risikopatienten.

\section{Hoch-Risiko:}

Alter > 60 Jahre oder thromboembolische bzw. schwere Blutungskomplikationen im Zusammenhang mit der ET oder Plättchenzahl $>1500 \times 10^{9} /$.

\section{Intermediär-Risiko:}

Keine Hochrisikokriterien erfüllt, und Thrombophiliemarker, oder Vorliegen eines kardiovaskulären Risikofaktors (arterielle Hypertonie, Diabetes mellitus, Hypercholesterinämie oder Nikotinabusus).

Niedrig-Risiko:

Alter < 60 Jahre und Plättchenzahl $<1500 \times 10^{9} / /$ und asymptomatisch oder nur Mikrozirkulationsstörungen.

\subsection{Therapieformen (Einzelheiten s. 2)}

- ASS 40-100 mg/Tag

- Zytoreduktive Behandlung mit Hydroxyurea (HU)

- Zytoreduktive Behandlung mit IFN oder mit pegyliertem IFN

- Behandlung mit Anagrelid 
Bei allen Therapieformen ist in der Regel eine Erhaltungstherapie erforderlich. Die Dosierungen sind im Verlauf den individuellen Werten des Blutbildes anzupassen. Der Zielwert der Thrombozytenzahl ist der Normbereich.

\section{Allgemeine Maßnahmen zur Senkung des Thromboembolierisikos:}

Gewichtsnormalisierung, regelmäßige Bewegung, Vermeiden von Exsiccose und langem Sitzen, Information der Patienten über Frühsymptome einer Thrombose und der Notwendigkeit eines sofortigen Arztkontaktes

Alle Patienten: Kardiovaskuläre Risikofaktoren (arterielle Hypertonie, Diabetes mellitus, Hypercholesterinämie oder Nikotinabusus) müssen effektiv behandelt werden

\section{Thrombozytenaggregationshemmer}

ASS 40 - $100 \mathrm{mg} / \mathrm{Tag}$ ist bei der ET von Nutzen, wenn folgende Beschwerden vorliegen: Erythromelalgie, transiente ischämische Attacken, koronare Ischämien oder Mikrozirkulationsstörungen. Kontraindikationen sind eine hämorrhagische Diathese oder ein anamnestisch bekanntes Ulkusleiden. ASS darf bei Plättchenzahlen von > 1 Million/ $\mu$ l nicht gegeben werden, da es hier häufig zu einem erworbenen vonWillebrand-Syndrom mit konsekutiver Blutungsneigung kommt.

Therapieindikationen nach Risikokonstellation

Bei Hochrisikopatienten immer Indikation zur zytoreduktiven Behandlung:

Patienten im höheren Lebensalter (s. 8.2) HU in einer Anfangsdosis von $20 \mathrm{mg} / \mathrm{kg}$ und einer Maximaldosis von $40 \mathrm{mg} / \mathrm{kg}$., bei Anämie und/ oder Leukozytopenie bei weiterbestehender Thrombozytose Anagrelid 1-2 mg

Jüngere Patienten: Die optimale therapeutische Strategie ist noch nicht eindeutig definiert. Die unter der HU-Behandlung nicht völlig ausgeschlossene Erhöhung des Risikos einer sekundären Leukämie oder anderer Neoplasien, hat zu einem zurückhaltenden Einsatz dieser Substanz bei jungen Patienten geführt. Die Frage ob bei diesen Patienten, oder bei älteren Patienten mit nicht tolerable Nebenwirkungen von HU zunächst Anagrelid oder IFN eingesetzt werden soll, ist nicht geklärt.

Anagrelid wird seit vielen Jahren in der Behandlung der ET eingesetzt. Die Nebenwirkungsrate ist akzeptabel, die Behandlungskosten sind wesentlich höher als unter HU. Die Ergebnisse der MRC-PT-1 Studie (27), in der auch bei jüngeren bei Hochrisikopatienten Hydroxyurea günstigere Resultate ergab als Anagrelid, sind nicht unproblematisch, da die Studie einige methodische Mängel aufweist. Die Ergebnisse der laufenden Anahydret-Studie, die ebenfalls $\mathrm{HU}$ mit Anagrelid vergleicht, sind noch nicht bekannt. Die in der PT-1 Studie gemachte Beobachtung, dass Patienten, die mit Anagrelid und Aspirin gleichzeitig behandelt wurden, eine erhöhte Blutungsneigung haben, ist von klinischer Relevanz.

IFN: (s. 2) wird ebenfalls seit vielen Jahren eingesetzt. Neuere Studien weisen darauf hin, dass pegyliertes IFN bei vergleichbarem Nebenwirkungs- und Wirkungsspektrum wegen der nur einmaligen Injektion pro Woche von vielen Patienten vorgezogen wird (34).

Bei den Intermediärrisiko-Patienten mit ET muss die Therapie auf den einzelnen Patienten zugeschnitten und die Vor- und Nachteile der bei den beiden anderen Gruppen dargestellten Alternativen mit diesem diskutiert werden, da die Behandlung dieser Risikogruppe bisher nur begrenzt durch publizierte Daten abgesichert ist. Bei fehlenden Kontraindikationen Einsatz von niedrig dosiertem Aspirin. 
Niedrig-Risiko-ET-Patienten: Bei diesen Patienten ist das Risiko thromboembolischer Komplikationen mit 2 Ereignissen auf 100 Patientenjahre nicht eindeutig erhöht (39). Der Nutzen der zytoreduktiven - oder ASS-Therapie ist nicht gesichert. Derzeit werden allgemeine Maßnahmen (s.o) und sorgfältige Überwachung in Hinsicht auf Übergang in eine höhere Risikogruppe empfohlen.

\subsection{Besondere Situationen}

\section{Kinderwunsch und Schwangerschaft}

Eine erfolgreiche Schwangerschaft ist bei über der Hälfte der Patientinnen zu erwarten (21). Die häufigste Komplikation ist ein Spontanabort im ersten Trimester der Schwangerschaft. Das Risiko für die Mutter ist gering, obwohl in Einzelfällen thrombotische oder hämorrhagische Komplikationen beschrieben wurden. Eine Interruptio aus medizinischen Gründen ist nicht angebracht. Die optimale Therapie während einer Schwangerschaft ist nicht bekannt; unter niedrig-dosierter ASS wurde eine höhere Rate erfolgreicher Schwangerschaften beobachtet. Sollte im Einzelfall eine Zytoreduktion während der Schwangerschaft erforderlich sein, scheint die Gabe von IFN am geeignetsten.

\subsection{Verlaufskontrollen}

- Klinische Untersuchungen, Blutbild mit Thrombozytenzahl: Abstände abhängig von der Therapieform und der Therapiephase sowie dem individuellen Verlauf der Erkrankung. In der Initialphase der Therapie kurzfristig alle 1-2 Wochen; nach Erreichen einer stabilen Phase in der Regel einmal monatlich.

- Halbjährlich Kontrollen des klinischen Status und der Laborbefunde unter Berücksichtigung zu erwartender Therapienebenwirkungen und Komplikationen der Erkrankung.

- Jährlich Sonographie des Abdomens.

- Die Knochenmarkverlaufsuntersuchungen zur Erfassung der seltenen Übergänge in eine akute Leukämie oder Myelofibrose richten sich nach dem Verlauf; in der Regel werden Untersuchungen alle 2-3 Jahre empfohlen (Zytologie und Histologie!)

\section{Idiopathische Myelofibrose / Osteomyelofibrose}

\subsection{Definition und Basisinformation}

Bei der idiopathischen Myelofibrose (cIMF), synomym auch als Osteomyelofibrose (OMF) bezeichnet; steht die frühzeitige Markfibrose, teilweise mit Osteosklerose und extramedullärer Hämatopoese und die frühzeitige Milzvergrösserung im Vordergrund. Über eine Freisetzung von Zytokinen wird frühzeitig eine reaktive Knochenmarkfibrose und eine Akkumulation und extramedullären Absiedlung von hämatopoetischen Stammzellen induziert. Die in Hinsicht auf primäre klinische Präsentation und Verlauf sehr vielfältige Erkrankung wurde mit verschiedenen Namen belegt, im angelsächsischen Sprachraum z. B. als "MMM" (myelofibrosis with myeloid metaplasia) oder "agnogenic myeloid metaplasia" bezeichnet. Die WHOKlassifikation unterscheidet ein hyperzelluläres Frühstadium der cIMF von den fortge- 
schritteneren Stadien mit zunehmender Knochenmarkfibrose. Die clMF ist abzugrenzen von sekundären Myelofibrosen als Folge von anderen myeloproliferativen Erkrankungen, soliden Tumoren oder von entzündlichen Erkrankungen. Die Prognose ist schlechter als die der übrigen Formen. Bei ausschliesslich supportiver Behandlung liegt die mediane Überlebenszeit mit grossen Unterschieden bei 1 bis 10 Jahren.

\subsection{Symptome und Befunde}

Anämiebedingte Leistungsminderung, uncharakteristische Allgemeinsymptome wie Nachtschweiss oder Gewichtsverlust und/oder durch die Splenomegalie bedingte Oberbauchbeschwerden sind die häufigsten Erstsymptome. Seltener sind gehäufte thromboembolische Ereignisse oder nicht exakt definierbare „rheumatische“ Gliederund Gelenkschmerzen (2).

Die Frühphase (präfibrotische Phase) oder das hyperzelluläre Stadium der clMF ähnelt dem Bild der ET mit oft exzessiver Thrombozytose, evtl. einer leichten Anämie und Leukozytose. Sie kann nur anhand der Knochenmarkveränderungen von dieser unterschieden werden. Die Milz ist zunächst nicht oder nur gering vergrößert. Entdeckt wird die Erkrankung in diesem Stadium oft als Zufallsbefund im Rahmen einer Routinelaborkontrolle oder im Zusammenhang mit der Abklärung einer zufällig entdeckten Splenomegalie. An klinischen Symptomen überwiegen die thromboembolischen Komplikationen.

Die Spätphase (fibrotische Phase), die sich im Extremfall als Osteomyelosklerose manifestieren kann, ist charakterisiert durch eine myeloische Metaplasie. Klinisch stehen Zeichen einer extramedullären Blutbildung oft mit massiver Hepatosplenomegalie und Lymphknotenschwellungen im Vordergrund. Das Auftreten von topischen myeloischen Metaplasien im fortgeschrittenen Krankheitsstadium ist zwar selten, kann aber fatale Folgen haben, wenn diese die Lunge, den Gastrointestinaltrakt, den Urogenitaltrakt oder das ZNS betreffen. Neben den Symptomen der extramedullären Hämatopoese stehen die Symptome der zunehmenden Panzytopenie (Anämiesymptome, Blutungen und Infekte) im Vordergrund. $2-10 \%$ der Patienten sterben an einer akuten myeloischen Leukämie, teilweise nach einem Zwischenstadium eines MDS (2;8;14;42;48).

\subsection{Diagnose}

Peripheres Blut: Anämie, leukoerythroblastisches Blutbild mit zum Teil deutlicher Vermehrung der Normoblasten und Linksverschiebung der Granulopoese bis hin zu Myeloblasten. Poikilozytose, Anisozytose, „Tränentropfenform“ der Erythrozyten. Absolute Retikulozytenzahl nicht oder nur inadäquat erhöht. In der Anfangsphase oft Thrombozytose und meist mässige neutrophile Leukozytose, aber auch Panzytopenie, die im Verlauf immer auftritt und schliesslich die klinische Problematik bestimmt. Erhöhte Harnsäure- und LDH-Werte. Splenomegalie und meist auch Hepatomegalie. Seltener bereits zum Diagnosezeitpunkt extramedulläre Hämatopoese (Haut, Lunge, paravertebral),

Diagnostisch entscheidend ist der Knochenmarkbefund. Zytologie meist unergiebig (Punctio sicca). Histologie: Im präfibrotischen Frühstadium erhöhte Zelldichte mit Vermehrung von grossen, polymorphen und atypisch verteilten Megakaryozyten und 
Vorstufen der Granulopoese (50). In anderen Fällen bereits initial ausgeprägte Markfibrose, zusätzlich in Abhängigkeit vom Entwicklungsstadium hämatopoetische Anteile nachweisbar, dabei weiterhin Dominanz atypischer Megakaryozyten. In Spätstadien nur noch Fibrose und Sklerose (46).

\subsection{Differentialdiagnosen}

Bei Patienten mit Hepatosplenomegalie, peripherer Zytopenie, leukoerythroblastischem Blutbild, Tränenzellen und typischer Knochenmarksmorphologie mit Fibrose ist die Diagnose clMF leicht zu stellen. Schwierigkeiten bereitet die Abgrenzung der hyperzellulären Form gegenüber der essentiellen Thrombozythämie und der fibrotischen Veränderungen gegenüber Myelofibrosen die aus einer Polycythaemia vera oder aus einer chronisch myeloischen Leukämie hervorgegangen sind. Es ist daher der Ausschluss eines Philadelphia-Chromosoms (t9:22) bzw. molekularbiologisch eines BCR-ABL-Fusionsgen erforderlich. Weitere Differentialdiagnosen, die mit einer (sekundären) Knochenmarkfibrose einhergehen, finden sich in der Tabelle 2.

Tabelle 2 Differentialdiagnosen der chronisch idiopathischen Myelofibrose

Hämatologische Erkrankungen (lymphoproliferative Erkrankungen) nicht hämatologische Erkrankungen

akute lymphatische Leukämie

Haarzellleukämie andere Non-Hodgkin Lymphome

Morbus Hodgkin

Multiples Myelom metastasierende solide Tumore

chronisch granulomatöse Infektionen

(z.B. Tuberkulose etc.)

systemischer Lupus Erythematodes oder andere Kollagenosen

renale Osteodystrophie

\subsection{Diagnostik}

Anamnese: Symptome mit Erhebung thromboembolischer Komplikationen und Blutungsereignisse, Begleiterkrankungen

\section{Körperliche Untersuchung}

\section{Sonographie des Abdomens zur Beurteilung von Leber und Milzgröße}

\section{- Röntgen Thorax, bei unklaren Herden Computertomographie}

- Labor: Blutbild einschließlich Differentialblutbild und Thrombozytenzahl, Retikulozyten, Quick, PTT, AST, ALT, YGT, alkalische Phosphatase, Bilirubin, Elektrolyte, Kreatinin, Harnsäure, LDH, direkter Coombstest

- Knochenmark: Zytologie und Histologie mit Eisen- und Faserfärbung, Mitbeurteilung in einem Referenzzentrum

- Nachweis der JAK2-Mutation. Im präfibrotischen Stadium Chromosomenanalyse oder molekulargenetische Untersuchung zum Ausschluß eines PhiladelphiaChromosoms. 


\section{Prognoseparameter}

In mehreren Studien wurden drei prognostisch bedeutsame Parameter identifiziert (7;16):

1. Hämoglobinkonzentration

2. Alter

3. Leukozytenzahl

Die Hämoglobinkonzentration steht dabei an erster Stelle. Eine Hämoglobinkonzentration von $<10 \mathrm{~g} / \mathrm{dl}$ ist ebenso wie eine Leukozytenzahl von $<4 \mathrm{G} / \mathrm{lbzw}$. $>30$ G/I mit einer kürzeren Lebenserwartung assoziiert (Tabelle 3). Über die Bedeutung der unreifen myeloischen Vorstufen im peripheren Blut bzw. der Ausschwemmung CD34 positiver Stammzellen als Prognoseparameter gibt es kontroverse Auffassungen. Ob unterschiedliche zytogenetische Aberationen für die Unterschiede in der Prognose verantwortlich sind, kann derzeit nicht beurteilt werden; ebenso ist die Bedeutung der JAK2 Expression für die Prognose der cIMF Patienten noch nicht umfassend genug untersucht.

\section{Tabelle 3 Prognostische Klassifikationen der cIMF (Lille Score)}

Hämoglobin $<10 \mathrm{~g} / \mathrm{dl}$

Leukozytenzahl < 4G/L oder > 30G/L

Präsenz eines dieser Befunde beträgt 1 Punkt

Mittleres Überleben:

Score 0: 93 Monate

Score 1: 26 Monate

Score 2: 13 Monate

\subsection{Therapie}

Die cIMF muss weiterhin als meist unheilbare Erkrankung betrachtet werden. Als wichtigster Grundsatz gilt in der palliativen Behandlung der cIMF Zurückhaltung in der Anwendung zytoreduktiver, strahlentherapeutischer und operativer Maßnahmen.

\subsubsection{Kurative Therapie}

Die einzige kurative Therapie ist die allogene SZT, die allerdings mit einer Transplantions-assoziierten Mortalität von bis zu $50 \%$ belastet ist $(6 ; 8)$. Bei jungen Patienten mit hohem Risiko und HLA-kompatiblem Spender, bei denen eine allogene SZT, vorzugsweise mit dosisreduzierten Konditionierung, in Frage kommt, ist bei grundsätzlichem Einverständnis für einen solchen Eingriff frühzeitig Kontakt mit einem Transplatationszentrum aufzunehmen. Dies gilt in jedem Fall für Kinder und Jugendliche. Hochdosistherapie mit autologer Stammzelltransplantation: Ermutigende Erfolge bei einigen Patienten, weiterhin nur in Studien.

\subsubsection{Palliative-symptomorientierte Therapie}

\section{Zytoreduktive Therapie.}


Obwohl der Effekt auf die Lebenserwartung nicht durch prospektiv randomisierte Studien gesichert ist, sprechen viele Beobachtungen für eine Verlangsamung der Progression, eine günstige Wirkung auf eine vorbestehende Anämie und eine zeitweise Verbesserung der Lebensqualität. Ein Versuch ist deswegen bei allen Patienten mit Symptomen oder Zeichen der Progredienz angebracht. Es kommen in Frage:

Primär HU, initial 0,5-1 g/Tag p.o. (15) bei Patienten im höheren Lebensalter (s.2) und bei allen Patienten bei denen eine Behandlung mit IFN wegen Nebenwirkungen abgebrochen werden muss

IFN, 3 Mio. IE s.c. $3 \times$ /Woche, evtl. Steigerung nach Blutbild und Verträglichkeit (15) bei allen jüngeren Patienten oder bei fehlendem Ansprechen auf Hydroxyurea

Thalidomid in einer Dosis von $50 \mathrm{mg} / \mathrm{d}$ bei weiterbestehenden symptomatischer Anämie, die auf andere Medikamente nicht anspricht (s.u.).

Anagrelid, das in einer Dosis von 0,5-3 mg/Tag ähnlich wie bei der essentiellen Thrombozythämie oder Polyzythämia vera die erhöhten Thrombozytenzahlen senkt. Der Effekt auf die klinisch relevanten Folgen und auf die Markfibrose ist noch nicht ausreichend untersucht.

\section{Anämie}

\section{Substitution von Blutprodukten}

Erythrozytenkonzentrate bei $\mathrm{Hb}<80 \mathrm{~g} / \mathrm{l}$ und bei klinischer Symptomatik. Gegebenenfalls Eisenentzug durch Chelate.

Androgene, z.B. Winobanin (Danazol${ }^{\circledR}$ ) 400-800 mg/Tag über mindestens zwei bis vier Monate (13). Unter Androgentherapie sollte regelmäßig die Glucosekonzentration kontrolliert werden. Bei weiblichen Patienten ist mit einem Hirsutismus zu rechnen

Erythropoetin: Bei fehlendem Ansprechen der Anämie auf Androgene und Serumerythropoetin unter $125 \mathrm{U} / \mathrm{I}$ Therapieversuch mit Erythropoetin $30000 \mathrm{E} /$ Woche, Ansprechen nach frühestens 2 Monaten zu erwarten, evtl. besseres Ansprechen bei zusätzlicher IFN-Gabe. Oft ist die Hämoglobinverbesserung nur passager. Bei Langzeittherapie ist mit einer Zunahme der Splenomegalie zu rechnen (8).

Kortikoide: bei autoimmunhämolytischer Anämie

Thalidomid mit oder ohne Kortikoiden in mittlerer Dosis. Derzeit ausserhalb von Studien Einzelfallbegründung erforderlich.

Lenalidomid (Revlimid $\circledast$ ) in Kombination mit Corticosteroiden ist zum gegenwärtigen Zeitpunkt die wirksamste Therapie zur Verbesserung der Anämie. Diese Aussage stützt sich auf noch sehr niedrige Fallzahlen. Für die cIMF noch nicht zugelassen, ausserhalb von Studien Einzelfallbegründung erforderlich. 
Splenektomie bei therapierefraktärer transfusionsbedürftiger Anämie und ausgeprägter Splenomegalie. Die Anämie ist bei sehr großer Milz häufig durch reversible Sequestration der Erythrozyten in der Milz bei normaler oder erhöhter Erythrozytenmasse bedingt. Vorbereitung und Entscheidungsfindung s. u.

\section{Symptomatische Splenomegalie}

Zytoreduktive Therapie s. o.

Milzbestrahlung mit kleinen fraktionierten Dosen. Nur unter Blutbildkontrolle, da Verstärkung von Anämie und Thrombozytopenie möglich.

Splenektomie: Postoperative Mortalität bis zu $30 \%$, aber in der Mehrzahl der Überlebern mehrjahrige Besserung des Allgemeinzustandes und der Anämie möglich, wenn histologisch Resthämopoese nachweisbar und das Erythrozytenvolumen normal oder erhöht ist. Bei Thrombozytose nur nach vorheriger zytoreduktiver Therapie. Wenn vom Blutbild her möglich, anschliessende Behandlung mit HU (s.o.), um rasch zunehmende Hepatomegalie zu vermeiden (44).

\subsection{Verlaufskontrollen}

- Körperliche Untersuchung, Blutbild und Sonographie des Abdomens, Abstände abhängig von der Therapieform und dem individuellen Verlauf der Erkrankung.

- Im Verlauf vierteljährliche Kontrollen des klinischen Status und der Laborbefunde, incl. Serumferritin.

-Die jährliche Untersuchung sollte mit Ausnahme der molekulargenetischen Befunde dem Programm der Diagnostik im Rahmen der Diagnosestellung entsprechen.

- Knochenmarkverlaufsuntersuchungen zur Erfassung der Progression oder der Übergänge in eine akute Leukämie richten sich nach dem individuellen Verlauf, in der Regel alle 1-2 Jahre.

\section{Nicht klassifizierbare cMPE und durch spezielle genomische Aberrationen gekennzeichnete Sonderformen}

\subsection{Definition und Basisinformation}

Bei einigen Patienten können die klinischen und laborchemischen Charakteristika zum Zeitpunkt der Diagnose keiner der klassischen cMPE-Entitäten zugeordnet werden und daher zunächst als unklassifizierbare cMPE bezeichnet. Mitunter ist insbesondere eine Abgrenzung zu bestimmten MDS-Subtypen schwierig und wird daher als MDS/MPE Übergangsform diagnostiziert.

Eine CML-typische Erkrankung ohne Ph-Chromosom und/oder BCR-ABL Fusionsgen wird als atypische CML bezeichnet. Unter Umständen kann bei 
deutlicher Monozytose im peripheren Blut eine chronische myelo-monozytäre

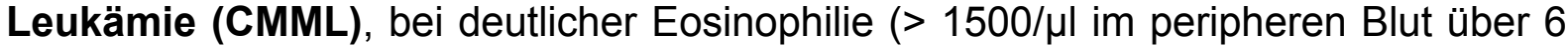
Monate) eine chronische Eosinophilenleukämie (CEL) diagnostiziert werden. Die Abgrenzung der CEL vom idiopathischen hypereosinophilen Syndrom (HES) ist häufig schwierig Bei Vermehrung von Blasten oder Nachweis einer Klonalität durch molekulargenetische Analysen ist eine CEL gesichert. Der Differentialdiagnose einer systemischen Mastozytose mit Eosinophilie sollte Rechnung getragen werden.

Neue molekulargenetische Erkenntnisse haben gezeigt, dass einigen dieser Entitäten aberrante Tyrosinkinase-Fusionsgene oder Punktmutationen innerhalb funktionell wichtiger Tyrosinkinase-Domänen zugundeliegen. Die dadurch entstehende Aktivierung der Tyrosinkinase ist der Pathogenese der BCR-ABL positiven CML vergleichbar. Der Nachweis von Fusionsgenen oder Punktmutationen durch Zytogenetik und Molekulargenetik ist für eine potentiell mögliche zielgerichtete Therapie („targeted therapy“), z. B. mit Imatinib oder anderen TK-Inhibitoren, von Bedeutung.

\subsection{Symptome und Befunde}

Aufgrund der klinischen Symptomatik lassen sich die Sonderformen der cMPE von den klassischen Formen in der Regel nicht unterscheiden. Häufige pathologische Befunde sind auch hier erhöhte Leukozytenzahl, hyperzelluläres Knochenmark, LDHErhöhung und Splenomegalie. Das Differentialblutbild ist hinweisend für HES/CEL und CMML. Die größten Schwierigkeiten bereitet hierbei die Differentialdiagnose der Eosinophilie zwischen reaktiven (z. B. bei Allergien oder Autoimmunerkrankungen), nicht-klonalen (z. B. lymphoproliferative Variante des HES) und klonalen (z. B. CEL) Formen. Für die CEL wegweisend sind Morphologie (Vermehrung von Blasten), Zytogenetik (Nachweis Klonalitäts-beweisender chromosomaler Aberrationen), FISH und PCR (Nachweis von Klonalitäts-beweisenden Fusionsgenen und Mutationen). Erhöhte Werte für die Serumtryptase finden sich bei der CEL und der systemischen Mastozytose. Die Morphologie des Knochenmarks ist hinweisend für CEL, CMML, MDS/MPE Übergangsformen und die systemische Mastozytose, eine Knochenmarkfibrose wird relativ häufig bei der FIP1L1-PDGFRA positiven CEL gefunden.

\subsection{Diagnostik}

- Blutbild- und Differentialblutbild

- Sonographie des Abdomens

- Serummultianalyse: Vitamin B12, LDH, Serumtryptase (bei FIP1L1-PDGFRA positiver CEL und SM erhöht) IgE (bei lymphoproliferativen Varianten des HES erhöht)

- Knochenmarkzytologie und -histologie (einschließlich Faserfärbung und Immunhistochemie für Tryptase und CD25 bei SM)

- Zytogenetik

- Molekulargenetik

- Ausschluss BCR/ABL, JAK2 
- Immer FISH oder RT-PCR für FIP1L1-PDGFRA bei nicht-reaktiver Eosinophilie

- Nachweis von Fusionsgenen entsprechend der Zytogenetik durch spezifische PCR oder FISH-Analyse

- Nachweis von Punktmutationen entsprechend der Morphologie (z. B. D816V KIT Mutation bei SM oder JAK2 bei atypischer CML, MDS/MPE). PRV1- bei unklassifizierbaren Formen

\section{4. .Therapie}

- Fusionsgene unter Beteiligung von PDGFRA oder PDGFRB: Imatinib 100 $400 \mathrm{mg}$ p.o. /Tag. Patienten mit Fusionsgenen unter Beteiligung von FGFR1 oder JAK2 sowie die häufigsten Punktmutationen (JAK2 positive MPE und D816V KIT positive SM) sind dagegen Imatinib-resistent.

- Ohne Nachweis einer molekularen Zielstruktur: zytoreduktive Therapie mit Hydroxyurea, bei ungenügender Wirkung Versuch mit IFN

- Bei jungen Patienten an allogene SZT denken

- Therapieversuch mit Immunsuppressiva bei idiopathischem HES

\subsection{Verlaufskontrollen}

- Klinische Untersuchung, Routinelabor

- Zytogenetik und RT-PCR bei Vorliegen von Fusionsgenen unter Beteiligung von PDGFRA oder PDGFRB wie bei BCR-ABL positiver CML in verlaufsbestimmten Intervallen.

- Knochenmarkzytologie und -histologie 


\section{Literatur}

(1) Anger B, Haug U, Seidler R, Heimpel H. Polycythemia vera. A clinical study of 141 patients. Blut 1989; 59:493-500.

(2) Anger B, Seidler R, Haug U, Popp C, Heimpel H. "Idiopathic myelofibrosis: a retrospective study of 103 patients". Haematologica 1990; 75:228-234.

(3) Bangerter $M$, Guthner $C$, Beneke $H$, Hildebrand A, Grunewald $M$, Griesshammer M. Pregnancy in essential thrombocythaemia: treatment and outcome of 17 pregnancies. Eur J Haematol 2000; 65(3):165-169.

(4) Barbui T, Barosi G, Grossi A, Gugliotta L, Liberato LN, Marchetti M et al. Practice guidelines for the therapy of essential thrombocythemia. A statement from the Italian Society of Hematology, the Italian Society of Experimental Hematology and the Italian Group for Bone Marrow Transplantation. Haematologica 2004; 89(2):215-232.

(5) Barbui T, Finazzi G. Clinical parameters for determining when and when not to treat essential thrombocythemia. Semin Hematol 1999; 36(1 Suppl 2):14-18.

(6) Barosi G, Bacigalupo A. Allogeneic hematopoietic stem cell transplantation for myelofibrosis. Curr Opin Hematol 2006; 13(2):74-78.

(7) Barosi G, Berzuini C, Liberato LN, Costa A, Polino G, Ascari E. A prognostic classification of myelofibrosis with myeloid metaplasia. $\mathrm{Br} \mathrm{J}$ Haematol 1988; 70:397-401.

(8) Barosi G, Hoffman R. Idiopathic myelofibrosis. Semin Hematol 2005; 42(4):248-258.

(9) Baxter EJ, Scott LM, Campbell PJ, East C, Fourouclas N, Swanton S et al. Acquired mutation of the tyrosine kinase JAK2 in human myeloproliferative disorders. Lancet 2005; \%19-25;365(9464):1054-1061.

(10) Boivin P. Indications, procedure and results for the treatment of polycythaemia vera by bleeding, pipobroman and hydroxyurea. Nouv Rev Fr Hematol 1993; 35:491-498.

(11) Cario H. Childhood polycythemias/erythrocytoses: classification, diagnosis, clinical presentation, and treatment. Ann Hematol 2005; 84(3):137-145.

(12) Cario H, Pahl HL, Schwarz K, Galm C, Hoffmann M, Burdelski M et al. Familial polycythemia vera with Budd-Chiari syndrome in childhood. $\mathrm{Br} \mathrm{J}$ Haematol 2003; 123(2):346-352.

(13) Cervantes F, Alvarez-Larran A, Domingo A, Arellano-Rodrigo E, Montserrat E. Efficacy and tolerability of danazol as a treatment for the anaemia of myelofibrosis with myeloid metaplasia: long-term results in 30 patients. $\mathrm{Br} \mathrm{J}$ Haematol 2005; 129(6):771-775.

(14) Cervantes F, Tassies D, Salgado C, Rovira M, Pereira A, Rozman C. Acute transformation in nonleukemic chronic myeloproliferative disorders: actuarial probability and main characteristics in a series of 218 patients. Acta Haematol 1991; 85:124-127.

(15) Dingli D, Mesa RA, Tefferi A. Myelofibrosis with myeloid metaplasia: new developments in pathogenesis and treatment. Intern Med 2004; 43(7):540547. 
(16) Dupriez B, Morel P, Demory JL, Lai JL, Simon M, Plantier I et al. Prognostic factors in agnogenic myeloid metaplasia: a report on 195 cases with a new scoring system. Blood 1996; 88(3):1013-1018.

(17) Goerttler PS, Kreutz C, Donauer J, Faller D, Maiwald T, Marz E et al. Gene expression profiling in polycythaemia vera: overexpression of transcription factor NF-E2. Br J Haematol 2005; 129(1):138-150.

(18) Goerttler PS, Steimle C, Marz E, Johansson PL, Andreasson B, Griesshammer $M$ et al. The Jak2V617F mutation, PRV-1 overexpression, and EEC formation define a similar cohort of MPD patients. Blood 2005; 106(8):2862-2864.

(19) Griesshammer M. Risk factors for thrombosis and bleeding and their influence on therapeutic decisions in patients with essential thrombocythemia. Semin Thromb Hemost. In press.

(20) Griesshammer M, Bangerter M, Sauer T, Wennauer R, Bergmann L, Heimpel $\mathrm{H}$. Aetiology and clinical significance of thrombocytosis: analysis of 732 patients with an elevated platelet count. J Intern Med 1999; 245(3):295-300.

(21) Griesshammer M, Grunewald M, Michiels JJ. Acquired thrombophilia in pregnancy: essential thrombocythemia. Semin Thromb Hemost 2003; 29(2):205-212.

(22) Griesshammer M, Klippel S, Strunck E, Temerinac S, Mohr U, Heimpel H et al. PRV-1 mRNA expression discriminates two types of essential thrombocythemia. Ann Hematol 2004; 83(6):364-370.

(23) Griesshammer M, Klippel S, Strunck E, Temerinac S, Mohr U, Heimpel H et al. PRV-1 mRNA expression discriminates two types of essential thrombocythemia. Ann Hematol 2004; 83(6):364-370.

(24) Gruppo Italiano Studio Policitimia. Polycythemia vera: the natural history of 1213 patients followed for 20 years. Ann Intern Med 1995; 123:656-664.

(25) Harris NL, Jaffe ES, Diebold J, Flandrin G, Muller-Hermelink HK, Vardiman J et al. World Health Organization classification of neoplastic diseases of the hematopoietic and lymphoid tissues: report of the Clinical Advisory Committee meeting-Airlie House, Virginia, November 1997. J Clin Oncol 1999; 17(12):3835-3849.

(26) Harrison C. Pregnancy and its management in the Philadelphia negative myeloproliferative diseases. Br J Haematol 2005; 129(3):293-306.

(27) Harrison CN, Campbell PJ, Buck G, Wheatley K, East CL, Bareford D et al. Hydroxyurea compared with anagrelide in high-risk essential thrombocythemia. N Engl J Med 2005; 353(1):33-45.

(28) Heimpel $\mathrm{H}$. The present state of pathophysiology and therapeutic trials in polycythemia vera. Int J Hematol 1996; 64:133-65.

(29) James C, Ugo V, Le Couedic JP, Staerk J, Delhommeau F, Lacout C et al. A unique clonal JAK2 mutation leading to constitutive signalling causes polycythaemia vera. Nature 2005; 434(7037):1144-1148.

(30) Johansson P. Epidemiology of the myeloproliferative disorders polycythemia vera and essential thrombocythemia. Semin Thromb Hemost 2006; 32(3):171173. 
(31) Jones AV, Kreil S, Zoi K, Waghorn K, Curtis C, Zhang L et al. Widespread occurrence of the JAK2 V617F mutation in chronic myeloproliferative disorders. Blood 2005; 106(6):2162-2173.

(32) Klippel S, Strunck E, Busse CE, Behringer D, Pahl HL. Biochemical characterization of PRV-1, a novel hematopoietic cell surface receptor, which is overexpressed in polycythemia rubra vera. Blood 2002; 100(7):2441-2448.

(33) Landolfi R, Marchioli R, Kutti J, Gisslinger H, Tognoni G, Patrono C et al. Efficacy and safety of low-dose aspirin in polycythemia vera. $\mathrm{N}$ Engl $\mathrm{J}$ Med 2004; 350(2):114-124.

(34) Langer C, Lengfelder E, Thiele J, Kvasnicka HM, Pahl HL, Beneke H et al. Pegylated interferon for the treatment of high risk essential thrombocythemia: results of a phase II study. Haematologica 2005; 90(10):1333-1338.

(35) Lengfelder E, Berger U, Hehlmann R. Interferon-alpha in the treatment polycythemia vera. Ann Hematol 1996; 79:103-109.

(36) Lengfelder E, Hochhaus A, Kronawitter U, Hoche D, Queisser W, Jahn-Eder M et al. Should a platelet limit of $600 \times 10(9) / l$ be used as a diagnostic criterion in essential thrombocythaemia? An analysis of the natural course including early stages. Br J Haematol 1998; 100(1):15-23.

(37) Robinson S, Bewley S, Hunt BJ, Radia DH, Harrison CN. The management and outcome of 18 pregnancies in women with polycythemia vera. Haematologica 2005; 90(11):1477-1483.

(38) Rozman C, Giralt M, Feliu E, Rubio D, Cortes MT. Life expectancy of patients with chronic nonleukemic myeloproliferative disorders. Cancer 1991; 67:26582663.

(39) Ruggeri M, Finazzi G, Tosetto A, Riva S, Rodeghiero F, Barbui T. No treatment for low-risk thrombocythaemia: results from a prospective study. $\mathrm{Br}$ J Haematol 1998; 103(3):772-777.

(40) Santhosh-Kumar CR, Yohannan MD, Higgy KE, Al-Mashhadani SA. Thrombocytosis in adults: Analysis of 777 patients. J Intern Med 1991; 229:493-495.

(41) Silver RT. Imatinib mesylate (Gleevec(TM)) reduces phlebotomy requirements in polycythemia vera. Leukemia 2003; 17(6):1186-1187.

(42) Tefferi A. Myelofibrosis with myeloid metaplasia. $N$ Engl J Med 2000; 342(17):1255-1265.

(43) Tefferi A. Polycythemia vera: a comprehensive review and clinical recommendations. Mayo Clin Proc 2003; 78(2):174-194.

(44) Tefferi A, Mesa RA, Nagorney DM, Schroeder G, Silverstein MN. Splenectomy in myelofibrosis with myeloid metaplasia: a single- institution experience with 223 patients. Blood 2000; 95(7):2226-2233.

(45) Temerinac S, Klippel S, Strunck E, Roder S, Lubbert M, Lange W et al. Cloning of PRV-1, a novel member of the UPAR receptor superfamily, which is overexpressed in polycythemia rubra vera. Blood 2000; 95(8):2569-2576.

(46) Thiele J, Chen Y-S, Kvasnicka HM, Diehl V, Fischer R. Evolution of fibroosteosclerotic bone marrow lesions in primary (idiopathic) osteomyelofibrosis 
a histomorphometric study on sequential trephine biopsies. Leukemia and Lymphoma 1994; 14:163-169.

(47) Thiele J, Kvasnicka HM, Diehl V. Initial (latent) polycythemia vera with thrombocytosis mimicking essential thrombocythemia. Acta Haematol 2005; $113(4): 213-219$.

(48) Thiele J, Kvasnicka HM, Steinberg Th, Zankovich R, Fischer R, Diehl V. Survival in primary (idiopathic) Osteomyelofibrosis, so-called agnogenic myeloid metaplasia. Leukemia and Lymphoma 1992; 6:389-399.

(49) Thiele J, Kvasnicka HM, Werden C, Zankovich R, Diehl V, Fischer R. Idiopathic primary osteomyelofibrosis: A clinico-pathological study on 208 patients. Leukemia and Lymphoma 1996; 22:303-17.

(50) Thiele J, Kvasnicka HM, Zankovich R, Diehl V. Clinical and morphological criteria for the diagnosis of prefibrotic idiopathic (primary) myelofibrosis. Ann Hematol 2001; 80(3):160-165.

(51) World Health Organisation. Tumours of the hemopoietic and lymphoid tissues. Lyon: IARCPress, 2001.

\section{Anschriften der Verfasser und der Mitglieder der Expertengruppe}

Prof. Dr. med. M. Griesshammer Innere Medizin III

Zentrum für Innere Medizin

Robert-Koch-Str. 8

$89081 \mathrm{UIm}$

E-Mail:

martin.griesshammer@uniklinik-ulm.de

Prof. Dr. med. H. Gisslinger

1.Medizinische Universitätsklinik

Innere Medizin

Lazarettgasse 14

A-1090 Wien

E-Mail:

heinz.gisslinger@akh-wien.ac.at

Prof. Emerit. Dr. med. H. Heimpel (Korr.) Innere Medizin III

Zentrum für Innere Medizin

Robert-Koch-Str. 8

$89081 \mathrm{Ulm}$

E-Mail:

hermann.heimpel@uniklinik-ulm.de
PD Dr. med. E. Lengfelder III. Medizinische Klinik Mannheim

Wiesbadener Straße 7-11

68305 Mannheim 31

E-Mail:

eva.lengfelder@t-online.de

Prof. Dr. med. A. Reiter

Klinikum Mannheim der Universität

Heidelberg

III. Medizinische Klinik

Wiesbadener Straße 7 - 11

68305 Mannheim

E-Mail:

andreas.reiter@med3.ma.uni-

heidelberg.de

Dr. med. H. Cario

Universitätsklinik für Kinder und

Jugendmedizin

Prittwitzstraße 43

89075 Ulm

E-Mail:

holger.cario@uniklinik-ulm.de 
Prof. Dr. med. H.H. Kreipe

Medizinische Hochschule Hannover Zentrum Pathologie u. Rechtsmedizin Carl-Neuberg-Str. 1 30625 Hannover

PD Dr. H. M. Kvasnicka Institut für Pathologie Joseph-Stelzmann-Straße 9 50931 Köln

Prof. Dr. med. .L. Pahl Klinik für Anästhesiologie Breisacherstr. 66 79106 Freiburg
Prof. Dr. med. J. Thiele Pathologisches Institut Josef-Stelzmannstr. 9 50931 Köln

Prof. Dr. med. A.J. Wehmeier Klinikum Remscheid

Burgerstr. 24

42859 Remscheid

PD Dr. med. R. Zankovich Internist/Hämatologie/Onkologie Josef-Haubrich-Hof 5 50676 Köln 